\title{
EXPERIÊNCIAS DE PARTICIPAÇÃO SOCIAL NA ELABORAÇÃO DO PLANO DIRETOR DE DESENVOLVIMENTO URBANO DE LIMA DUARTE
}

\author{
Lívia Ribeiro Abreu Muchinelli ${ }^{1}$
}

\author{
Bárbara Lopes Barbosa ${ }^{2}$
}

\begin{abstract}
RESUMO
Este trabalho objetiva trazer algumas reflexões acerca da metodologia participativa desenvolvida e das dificuldades estruturais encontradas na elaboração do Plano Diretor Participativo (PDP) do município de Lima Duarte, na Zona da Mata de Minas Gerais. Este plano foi desenvolvido através de um convênio firmado entre Prefeitura do município e a Universidade Federal de Juiz de Fora entre os anos de 2012 a 2014 e envolveu distintas áreas de conhecimento técnico e acadêmico, além de moradores do município, que contribuíram com o planejamento local, ao repassar sua experiência a partir da vivência da cidade. A experiência aqui relatada e analisada trata da realidade de um município de pequeno porte e segue o planejamento sugerido pelo Estatuto da Cidade. Cabe assim, discutir este processo de elaboração, que passou por dificuldades bastante comuns em experiências de planejamento em cidades com perfis semelhantes relacionados à estrutura administrativa, cultura política e capacidade de articulação.
\end{abstract}

PALAVRAS-CHAVE: Participação Social e Plano Diretor Participativo e Estatuto das Cidades.

\section{EXPERIENCE OF SOCIAL PARTICIPATION IN THE PREPARATION OF 'PLANO DIRETOR DE DESENVOLVIMENTO URBANO DE LIMA DUARTE'}

\begin{abstract}
This paper aims to bring some reflections on participatory methodology developed and structural difficulties in the preparation of a management plan (Plano Diretor Participativo - PDP) in the city of Lima Duarte, Zona da Mata, Minas Gerais. This plan was developed through an agreement between the municipality and 'Universidade Federal de Juiz de Fora', between the years 2012 to 2014 and involved different areas of technical and academic knowledge, and county residents who have contributed to the local planning to pass on their experience about the city. The experience here reported and analyzed deals with the reality of a small city and follows the plan suggested by the 'Estatuto da Cidade'. It therefore, necessary discuss this process, which went

\footnotetext{
${ }^{1}$ Doutoranda no programa de Pós graduação da Universidade de São Paulo. E-mail: liviamuchinelli@gmail.com

${ }_{2}$ Mestranda do Programa de Pós-graduação em Arquitetura e Urbanismo pela Universidade Federal da Bahia. E-mail: blb.arq.urb@gmail.com
} 
through quite common difficulties in experiences of planning in cities with similar profiles related to the administrative structure, political culture and joint capacity.

KEY-WORDS: Social Participation, 'Plano Diretor Participativo', 'Estatuto das Cidades'

\title{
EXPERIENCIA DE PARTICIPACIÓN SOCIAL EM LA PREPARACIÓN DEL 'PLANO DIRETOR DE DESENVOLVIMENTO URBANO DE LIMA DUARTE'
}

\begin{abstract}
RESUMEN
Este trabajo tiene como objetivo hacer algunas reflexiones sobre metodologías participativas desarrolladas y dificultades estructurales en la preparación de un plan de gestión (Plano Diretor Participativo - PDP) en la ciudad de Lima Duarte, Zona da Mata de Minas Gerais. Este plan fue desarrollado a través de un acuerdo entre el municipio y 'Universidade Federal de Juiz de Fora', entre los años 2012 a 2014 y envolvió diferentes áreas de conocimiento técnico y académico, y los residentes de la ciudad que han contribuido a la planificación local para transmitir su experiencia a partir de la ciudad. La experiencia aquí reportada y analizada con la realidad de una ciudad pequeña sigue el plan sugerido por el Estatuto de la Ciudad. Por lo tanto se discute este proceso, que pasó por dificultades bastante comunes en las experiencias de planificación en ciudades con perfiles similares relacionados con la estructura administrativa, la cultura política y la capacidad conjunta.
\end{abstract}

PALABRAS-CLAVE: participación social, 'Plano Diretor Participativo', 'Estatuto das Cidades'.

\section{INTRODUÇÃO}

O objetivo deste trabalho é trazer algumas reflexões acerca da metodologia participativa desenvolvida e das dificuldades estruturais encontradas na elaboração do Plano Diretor Participativo (PDP) do município de Lima Duarte, na Zona da Mata de Minas Gerais.

O plano em questão foi desenvolvido através de um convênio firmado entre a Prefeitura do município e a Universidade Federal de Juiz de Fora (UFJF) através do Centro de pesquisas Sociais, entre os anos de 2012 a 2014. Nesta oportunidade, a UFJF disponibilizou bolsistas de diversas áreas de conhecimento e convidou profissionais ligados à área acadêmica para compor o corpo técnico interdisciplinar que auxiliou o município em todo o processo. 
Revista Nacional de

Gerenciamento de Cidades

Assim, a experiência aqui relatada e analisada trata da realidade de um município de pequeno porte, planejada à luz do Estatuto da Cidade. Cabe assim, discutir este processo de elaboração, que passou por dificuldades bastante correntes na questão da participação social, em experiências de planejamento em cidades com perfis semelhantes. Estas dificuldades estão geralmente relacionadas à estrutura administrativa, cultura política e capacidade de articulação dos agentes sociais destes municípios.

Um Plano Diretor conta com as diversas áreas de conhecimento para compreender a multiplicidade de funções que uma cidade comporta. E, além dos detentores destes conhecimentos, o planejamento municipal abarca os atores ligados à sua administração e presentes na vivência cotidiana da cidade.

A cidade, por estar envolvida nos processos de socialização das pessoas que a constituem, não pode ser vista como uma construção artificial. Segundo Lefebvre (1991), ela é a materialização da vivência de seu espaço e por isso, apesar de ser identificada como um produto, ela carrega os elementos da vida social que ali se desenvolve, não é apenas uma construção física.

Para que a Função Social da Propriedade urbana seja o mote das políticas de desenvolvimento urbano, o plano diretor precisa ser amplamente debatido pela população em todo seu processo. Deve-se assim, estabelecer um planejamento participativo contínuo, como forma de garantir a gestão democrática da cidade, o que na prática, geralmente, é seu maior desafio.

Para tanto, será apresentado o município de Lima Duarte e a elaboração de seu Plano Diretor como objeto de estudo; as normas e conceitos norteadores da metodologia aplicada ao projeto; a relação estabelecida entre estes conceitos e as particularidades deste município; além do relato dos momentos de participação social efetiva; a fim de refletir acerca das condições de participação comunitária e sua metodologia institucionalizada, assim como os desafios da prática participativa no planejamento urbano. 


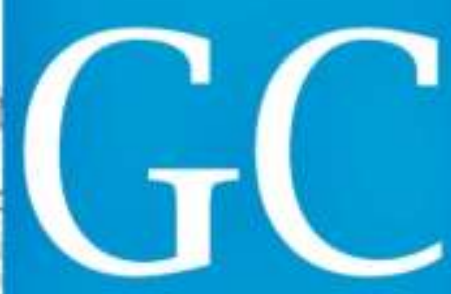

Revista Nacional de

Gerenciamento de Cidades

\section{O MUNICÍPIO DE LIMA DUARTE EM MINAS GERAIS}

Localizado a sudeste do estado de Minas Gerais, Lima Duarte integra a Região de Planejamento da Zona da Mata, em plena Região das Conclusões da Serra da Mantiqueira. Conforma-se em uma área de $850 \mathrm{Km}^{2}$ em Região Montanhosa e de hidrografia abundante.

A cidade atualmente possui uma população urbana de 11.309 e rural de 4.399, totalizando 15.708 habitantes, segundo dados do Censo IBGE - 2000. Ela é conformada pelo Distrito Sede e mais três distritos, São Domingos da Bocaina, Conceição do Ibitipoca e São José dos Lopes, tendo atrativos turísticos consolidados, ou em potencial, em todos estes distritos.

Nos anos 1980, há a entrada de um novo e promissor setor econômico no município, o turismo, que vem crescendo cada vez mais na região a partir da criação do Parque Estadual de Ibitipoca em seu território.

Figura 1: Localização do município de Lima Duarte e sua divisão em distritos

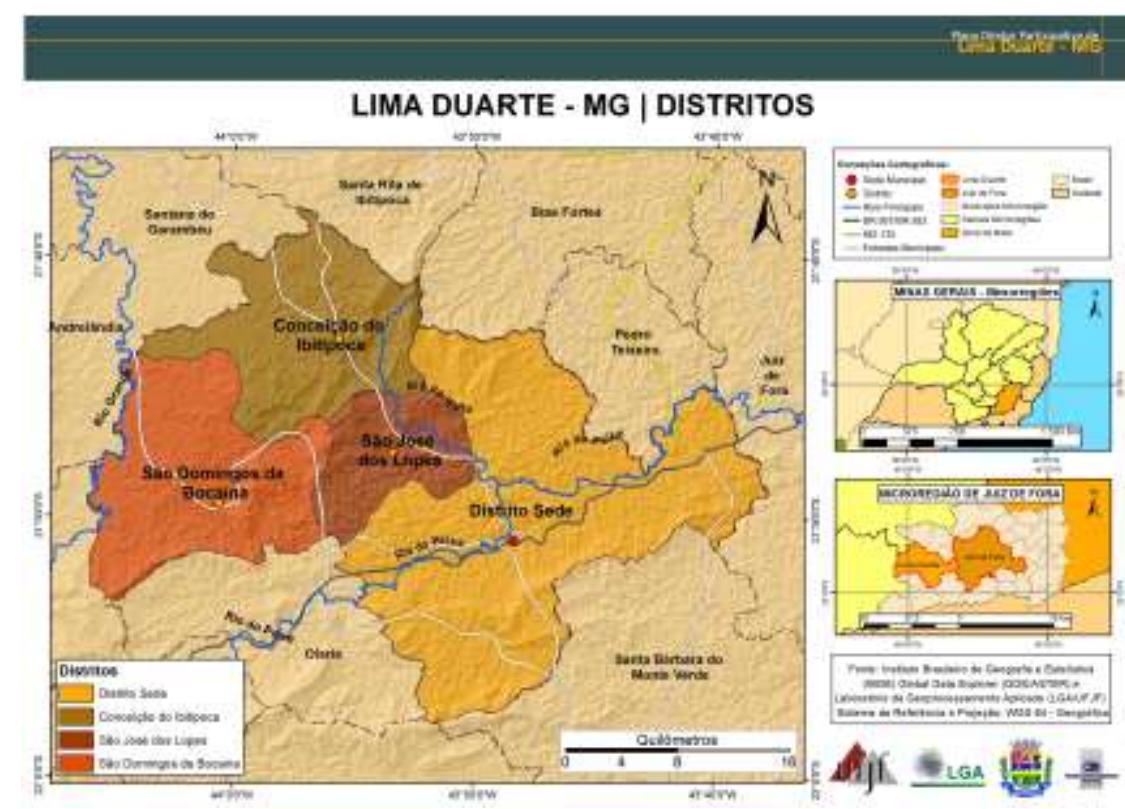

Fonte: Produto 03 - Leitura da realidade local, PDP. 2014. 
Revista Nacional de

Gerenciamento de Cidades

Com a prática do eco turismo nota-se uma valorização crescente da terra, principalmente no Distrito de Conceição do Ibitipoca, onde está localizado o Parque. Contudo, este cenário potencializa a existência de grandes conflitos econômicos, e de uso da terra, motivados pela valorização e especulação imobiliária, que tem acompanhado o turismo local. Estes conflitos interferem diretamente na participação social, eles trazem para estes espaços interesses econômicos pessoais que imobilizam os interesses coletivos e a preocupação com a função social da terra no município.

Ainda no panorama econômico, a cidade possui uma produção agropecuária considerável e, cooperativas de produção agrícola familiar e de laticínios, com produção relativamente grande para o porte do município.

Apesar da proximidade com a cidade de Juiz de Fora, polo regional, e a facilidade de acesso às estradas federais e estaduais, o município possui dificuldades de ligação intramunicipal e inter-regional, a princípio por se tratar de um município extenso e por possuir vias de ligação de qualidade ruim, agravadas pelo terreno geralmente acidentado, são estas, questões que dificultam de certa forma a circulação das informações em seu território.

\section{A PARTICIPAÇÃO SEGUNDO O ESTATUTO DA CIDADE: METODOLOGIAS E AÇÃo}

Em 2001, após doze anos de lutas sociais, foi aprovado o Estatuto da Cidade, avaliado como uma das grandes conquistas do Movimento pela Reforma Urbana desenvolvido nos anos de 1980. Este é o nome dado à Lei Federal $n^{\circ}$ 10.257, que regulamenta os artigos 182 e 183 da Constituição Federal de 1988 (CF/88) e trata da política urbana no Brasil.

Com base no princípio da função social da propriedade e gestão democrática da cidade, a lei contém normas de ordem pública e interesse social regulando 
o uso da propriedade urbana de modo a garantir o bem coletivo, a segurança e o bem-estar dos cidadãos. (SAULE JÚNIOR e UZZO; 2009. pág. 6).

Um dos grandes avanços trazidos pelo Estatuto da Cidade está em seu capítulo IV que trata da "Gestão democrática da cidade". Este capítulo apresenta instrumentos de participação social, como a criação de órgãos colegiados de política urbana, debates, audiências e conferências, além da possibilidade de proposição de políticas públicas, projetos de leis e programas de desenvolvimento urbano, através da iniciativa popular, representando a base metodológica que guia a gestão democrática das cidades. O Estatuto traz, ainda, a obrigatoriedade de envolvimento social no desenvolvimento dos planos diretores municipais, ponto fundamental nesta abordagem.

Por apresentar diretrizes gerais de política urbana, o Estatuto, deixou a cargo de cada Município efetivar os dispositivos que deverão regulamentar o Plano Diretor, segundo as características locais. O Plano é, na maioria das vezes, o mais completo instrumento de planejamento dos municípios, trazendo com ele diversas ferramentas para colaborar com sua aplicação.

De acordo com o Estatuto das Cidades, a participação no desenvolvimento dos planos diretores deve ser realizada através da promoção de audiências públicas e debates com a presença e participação da população, e de associações representativas dos vários segmentos da comunidade, e da publicidade e do acesso de qualquer interessado aos documentos e informações produzidos. A não observância destes pontos pode acarretar não só na não aprovação da lei, mas também na sanção, por improbidade administrativa dos agentes públicos responsáveis.

É importante destacar que além da participação popular na elaboração do Plano Diretor, o sucesso de sua implementação depende do entendimento por parte da população dos instrumentos possíveis de serem aplicados em sua cidade. A fiscalização também esta sujeito à participação, assim como a cobrança de atitudes e políticas estipuladas pelo Plano. 
Revista Nacional de

Gerenciamento de Cidades

De acordo com o Ministério das Cidades, o processo de elaboração do Plano Diretor pressupõe a realização de, pelo menos, quatro etapas: apresentação da metodologia, leitura da realidade municipal, seleção e pactos em relação a temas prioritários e elaboração do projeto de lei do plano diretor.

Assim, construindo uma metodologia sobre este processo, as etapas de trabalho se distribuíram em: Plano Executivo; Leitura Técnica e Comunitária da Realidade Municipal; Diagnóstico Consolidado; Discussão de Propostas com a comunidade; e Caderno do PDP com as metas, propostas e diretrizes para os temas prioritários e definição de instrumentos e planos complementares.

Deste modo, para o desenvolvimento do PDP de Lima Duarte, a equipe técnica elaborou um cronograma de participação comunitária, buscando através de ferramentas de comunicação contínua, mobilização, divulgação, e discussão coletiva, aproximar a sociedade deste processo, que será descrito no item que se segue.

\section{RESULTADOS: OS DESAFIOS DA PARTICIPAÇÃO COMUNITÁRIA}

Ao iniciar os trabalhos, foi feita uma audiência na sede municipal, onde as definições e objetivos de um plano diretor foram apresentados aos moradores do município, destacando a importância da participação comunitária no processo. Foram discutidas as melhores estratégias de comunicação e divulgação, assim como apresentado e discutido o cronograma de ações; ferramentas como, e-mail e informativos nas redes, sociais foram levantados como possíveis canais de comunicação, além da necessidade de contato constante com as lideranças comunitárias de cada localidade do município.

Além disso, reuniram-se os técnicos da prefeitura e representantes do legislativo, buscando mobilizá-los e capacitá-los para que a elaboração do plano contasse desde o princípio com a participação destes setores. 
Figura 2: Audiência de Abertura do processo de elaboração do PDP

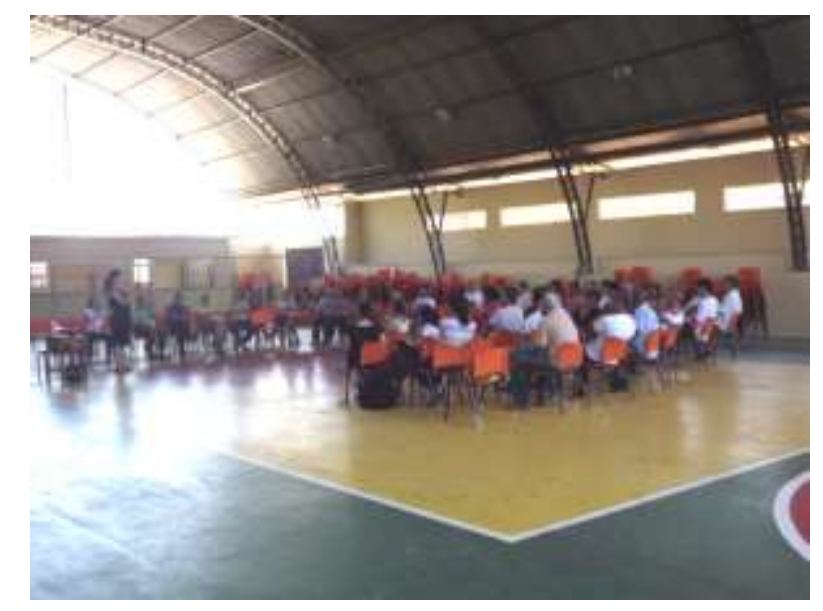

Fonte: Produto 04 - Relatório de Participação Social e Mobilização Comunitária, PDP. 2012.

Nesta sequência, foram desenvolvidos levantamentos documentais, visitas de campo, com diferentes focos, de acordo com as Áreas de Concentração e de Conhecimento Técnico, além de entrevistas específicas com os atores locais e técnicos da prefeitura. Ao fim de todos os levantamentos, foi realizada a análise, organização e leitura do material coletado, com o auxílio dos bolsistas de áreas multidisciplinares envolvidos no projeto, que resultaram na confecção dos relatórios técnicos.

Em paralelo, foram desenvolvidos materiais de capacitação comunitária para serem distribuídos pela internet e através da prefeitura às comunidades urbanas e rurais, partindo do entendimento de que a discussão feita com uma comunidade desinformada ou despreparada é um simples cumprimento de etapas, sem efeitos no desenvolvimento social do município. O material de capacitação consistia de cartilha de formação e conhecimento dos instrumentos trabalhados, além de folders com informações específicas a cerca de temas considerados prioritários a partir das informações coletadas.

Assim que este pré-diagnóstico alcançou um nível de consistência de informações, foi organizado um material para ser apresentado à população no 


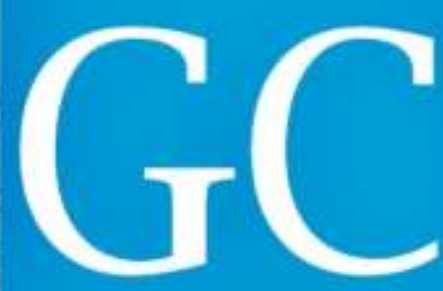

Revista Nacional de Gerenciamento de Cidades

formato de oficinas comunitárias, com 0 intuito de despertar 0 interesse nos assuntos que seriam discutidos, analisados, complementados e criticados.

As oficinas foram marcadas em cinco localidades diferentes dentro do município, com o intuito de atingir de forma mais abrangente o território de Lima Duarte, buscando alcançar, assim, o maior número possível de representantes locais e dos moradores destas comunidades como um todo.

Nestas oficinas, o projeto foi apresentado e as informações preliminares expostas. Em cada comunidade, a coleta de informações e críticas foi variada. Além disso, novas questões e temas surgiram.

Durante estas discussões, a população era convidada a expor sua opinião acerca de temas gerais como saúde, educação, turismo, lazer, cultura, etc., dentro daquela localidade. Através de diferentes formas de abordagem a comunidade expressou anseios e metas para o distrito e para o município como um todo, e com o auxilio da equipe técnica, começou-se a explorar o que era possível fazer através das leis urbanas, das propostas de políticas públicas e dos instrumentos de planejamento, que podem estar presentes no plano diretor, e as diferentes opiniões foram debatidas entre os moradores.

Figura 3 E 4: Oficinas Comunitárias em São Domingos da Bocaina e em São José dos Lopes da esquerda para a direita
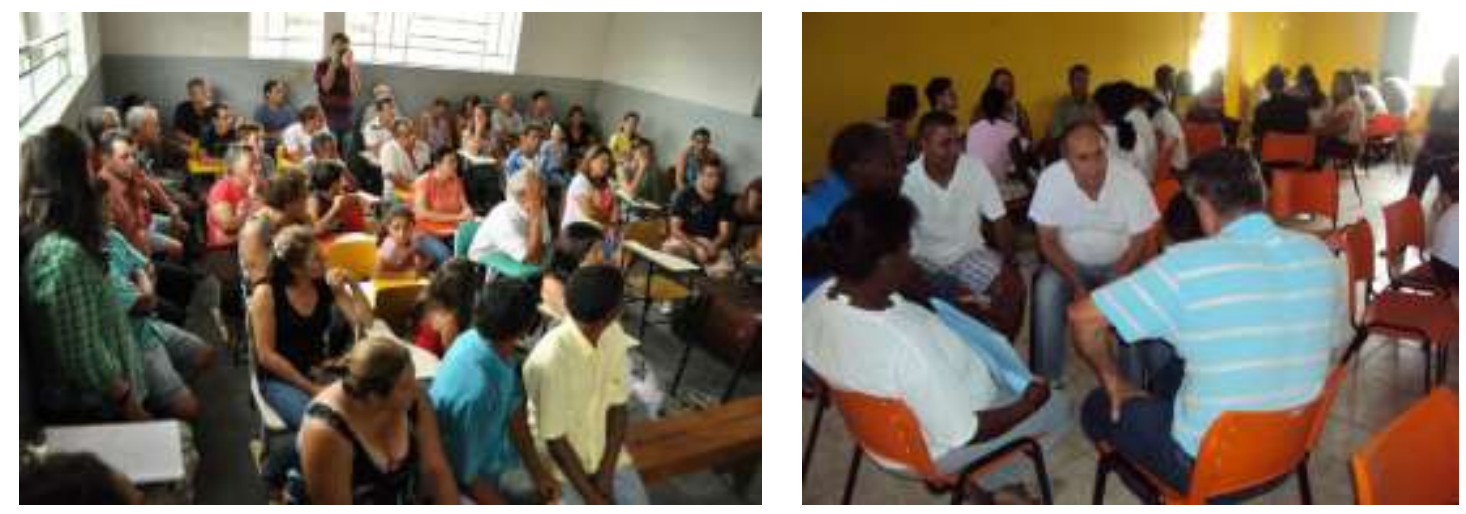

Fonte: Produto 04 - Relatório de Participação Social e Mobilização Comunitária, PDP. 2013. 
Revista Nacional de

Gerenciamento de Cidades

Nestas oficinas foram escolhidos os representantes que vieram a compor o Núcleo Gestor do Plano Diretor Participativo. Este Núcleo foi responsável por facilitar a comunicação entre o corpo técnico e a comunidade, além de fiscalizar o andamento do projeto e seus produtos. Toda a documentação e relatoria foram disponibilizadas para a população através da prefeitura e da equipe técnica, contando com o auxílio da internet, pelas redes sociais ou correio eletrônico, ao longo de todo o processo.

O Documento produzido após este momento, que refletia a Leitura da realidade municipal, foi repassado ao núcleo gestor e para a equipe da administração pública para avaliação e revisão. O núcleo gestor recebeu a incumbência de levantar, nas associações e localidades, que representam, as discussões sobre o material.

As etapas seguintes seguiram estratégias de mobilização e discussão semelhantes, com oficinas comunitárias e reuniões com o núcleo gestor, que objetivaram debater as potencialidades e soluções dos diferentes temas relacionados ao desenvolvimento urbano, e, por fim, audiências públicas que tinham o intuito de aprovar cada etapa do trabalho publicamente.

Os canais de comunicação via internet foram utilizados como ferramentas de aproximação. Além da utilização do correio eletrônico, foi criada uma página e perfil em rede social, como forma de atingir mais rapidamente os moradores, principalmente os jovens, que costumam estar mais conectados a esta forma de comunicação. Alguns elementos destes canais foram ampliados por sugestão da própria comunidade, como a abertura de um grupo específico para discussões das propostas levantadas, nesta mesma rede social.

Entretanto, a metodologia planejada e aplicada esbarrou em problemas de diversas naturezas.

A participação comunitária, ainda que, tendo como premissa o fortalecimento do tecido social, buscando delegar a sua população o protagonismo da intervenção na projeção de suas demandas e interesses, competindo em condições de 
Revista Nacional de

Gerenciamento de Cidades

igualdade e regras comuns a todos os cidadãos, sofre influências de agentes externos e está subordinada ao desejo de envolvimento dos cidadãos.

Assim, mesmo havendo um método de abordagem claro e inclusivo, a participação social é distinta em cada município. Algumas experiências são colocadas como positivas e replicadas, mas em cada lugar assumem resultados diferentes. Desta forma, não existe uma receita para que o público compareça, para que participe e se envolva efetivamente, e para que a importância dada a cada ponto seja tal qual a planejada.

No tocante a particularidade de Lima Duarte, na elaboração do Plano Diretor, considera-se que a participação foi bastante relativa, especialmente as reuniões nas comunidades rurais, apesar da noção de planejamento em longo prazo ser por vezes desconsiderada e substituída por problemas imediatos.

Tais fatos são justificados, ora pela falta de conhecimento acerca das possibilidades que a legislação e o planejamento trazem, ora pela falta de espaços de participação das gestões públicas. Desta forma, quando se abre o espaço para a participação, a concentração de demandas pontuais e imediatas é insurgente e predominante. Apesar da tentativa de capacitação, a comunidade vem de uma cultura assistencialista e pouco participativa.

É importante destacar que esta não é uma realidade especial de Lima Duarte, mas uma questão recorrente em muitos municípios brasileiros, onde a participação social é, ainda, muito imatura. De forma geral, no Brasil, não existe uma cultura onde as soluções urbanas vêm da base social para os gestores. O planejamento tem um histórico de soluções verticais, onde os técnicos possuem as soluções e a comunidade assume o papel de espectador.

Outro conflito enfrentado nos espaços de participação do processo de elaboração do plano se estabeleceu no envolvimento do poder executivo e legislativo nas reuniões e oficinas comunitárias. A priori, a participação destes setores é de fundamental importância para o desenvolvimento do PDP, já que este envolvimento pode dar agilidade ao momento de discussão posterior, e até reduzir a 
Revista Nacional de

Gerenciamento de Cidades

necessidade de revisões e alterações do projeto de lei na câmara, por exemplo, sendo realmente fiel aos interesses da população.

Esta participação deve ser consciente da importância deste momento e da duração do plano diretor, vendo-o vinculado não àquela gestão, mas ao planejamento do município de forma global, e por um período que vai além da gestão em si.

É necessário, portanto, o preparo técnico e conceitual dos vereadores, técnicos, secretários e prefeitos a respeito da necessidade de um planejamento que entenda as necessidades do município em longo prazo, do contrário, os pontos individuais prevalecem, as soluções imediatistas acabam sendo destacadas e o propósito da elaboração do plano se perde nestas questões.

$\mathrm{Na}$ experiência de Lima Duarte, talvez por uma falta de aparelhamento destes técnicos aos objetivos do plano, as questões emergenciais e os problemas pontuais da gestão ocuparam a maior parte de muitos dos debates desenvolvidos, sendo a participação da comunidade, por vezes, talhada por discursos e soluções imediatistas que envolviam mais propriamente a ação emergencial da estrutura já existente da gestão.

A isto se soma a falta de preparo técnico para desempenho das funções de alguns dos indicados para conduzir as secretarias e departamentos da administração municipal, sendo estas escolhes guiadas por questões absolutamente políticas, desconsiderando, por muitas vezes, o conhecimento específico da função a ser desempenhada.

Volta-se à herança tão marcante do 'paternalismo' e do 'clientelismo', elementos existentes em nosso país que, desde a época colonial, que representam a utilização de soluções provenientes de uma pessoa _ um pai, um "protetor" daquela comunidade, que mantem sua subordinação a ele _ não advém da coletividade. $^{3}$

\footnotetext{
${ }^{3}$ Os temas do 'paternalismo' e do 'clientelismo' são tratados em diversos textos de autores, tais como Ermínia Maricato e Florestan Fernandes, a fim de explicitar as relações de dependência que se
} 
Revista Nacional de

Gerenciamento de Cidades

Além destes problemas citados, bastante recorrentes em muitos municípios brasileiros, como já mencionado, houve um agravante na experiência aqui descrita que se refere à mudança de gestão, ainda na segunda etapa do desenvolvimento do projeto. A troca de gestão, somada à permuta dos partidos à frente da administração, pode ser considerada uma causa extremamente relevante ao se tratar das distorções de objetivos, prioridades e perspectivas de planejamento de cada gestão.

Ao longo da realização das oficinas realizadas, os problemas que envolvem os caminhos da participação comunitária foram percebidos pela equipe técnica e, suas possíveis soluções, foram discutidas, conforme as possibilidades de ação da mesma.

Questões como falta de compromisso, por parte da administração local em divulgar a marcação de reuniões, oficinas e audiências, com a abrangência necessária, trouxe a necessidade de constantes alterações de datas para realização das atividades.

Além disso, a extensão do município foi um entreposto para reuniões mais constantes do núcleo gestor com a equipe técnica. Consequentemente, o repasse para as comunidades foi mais contido do que o planejado.

Os canais criados na internet constituem um importante avanço no contato imediato e abrangente para divulgação e informação, entretanto, em um município com tamanha extensão rural, como é o caso de Lima Duarte, este método deixa a desejar em sua eficiência, sendo atingidas pessoas de núcleos já mais mobilizados, que são também alcançados por outros meios.

configuram entre as diferentes classes sociais no Brasil, assim como entre os países capitalistas periféricos e centrais, e que são as principais responsáveis por manter o subdesenvolvimento e a estagnação econômica e social. Alguns dos títulos são "Metrópole na periferia do capitalismo: ilegalidade, desigualdade e violência" (1995), da primeira, e "Capitalismo dependente e classes sociais na América Latina" (2009), do último. 
Revista Nacional de

Gerenciamento de Cidades

\section{CONSIDERAÇÕES FINAIS}

A participação popular na elaboração de políticas públicas é recente no país, em consequência disso, observou-se, através das oficinas, a falta de senso comunitário das pessoas, a dificuldade de se pensar nos problemas gerais do local e não pontuais. É importante deixar claro para a população que esse é o momento para acompanhar e fiscalizar o cumprimento das proposições do plano diretor, já que são essas as pessoas diretamente afetadas pelo plano.

Objetiva-se despertar e orientar o efetivo envolvimento da população nas questões públicas e a compreensão por parte das autoridades locais de que o plano diretor vai além de uma gestão, com resultados a longo prazo. Não basta dizer à comunidade qual o seu papel, é necessário expor instrumentos que existem para tal participação e orientá-la sobre como utilizá-los.

Uma das soluções para esta questão poderia ser, por exemplo, uma capacitação mais aprofundada, começando na educação jovem, para que o senso coletivo e a consciência politizada se torne a base de cada cidadão.

Entretanto, é um equívoco colocar como simples culpada a comunidade e sua falta de articulação ou preparação para a participação democrática, pois é recorrente a existência de espaços de representação corrompidos e falidos, como os próprios conselhos municipais, nos quais é necessária uma grande reestruturação.

Além disso, são realizadas mudanças na lei, já no âmbito do poder legislativo, que muitas vezes, desmerecem todo o trabalho técnico e comunitário, em algumas ocasiões, motivadas por interesses econômicos particulares, práticas consolidadas ao longo da história do Brasil.

A participação da universidade nestes espaços se mostra importante, por, de um lado, preparar os acadêmicos para a atuação profissional, fortalecendo um olhar voltado para as necessidades sociais e, por outro, da troca de conhecimentos com a comunidade, que busca se instrumentalizar para participar e efetivar as políticas para melhoria de seu município. 


\section{Revista Nacional de}

A metodologia aplicada deve ser debatida e aperfeiçoada, buscando uma melhor integração e diálogo claro entre equipe técnica, administração pública e comunidade. Momentos como este evento, entre outros, proporcionam discussões e trocas de informações e experiências entre acadêmicos e profissionais que contribuem para evoluir e repensar cada vez mais os instrumentos de participação popular.

É importante destacar que, além da participação popular na elaboração do Plano Diretor, o sucesso de sua implementação depende do entendimento por parte da população dos instrumentos possíveis de serem aplicados em sua cidade. A fiscalização também depende da participação, assim como a cobrança de atitudes e políticas estipuladas pelo Plano.

A ação do Estado na criação de normas e na manutenção da ordem pode equilibrar o interesse coletivo frente ao individuo. Entretanto, é preciso lembrar, que o Estado age não somente como mediador, mas como agente direto na produção do espaço urbano.

Neste sentido, Maricato (2011) enfatiza a tradição arbitrária da aplicação das leis do Brasil, chamando a atenção que, o funcionamento das políticas públicas e garantia da função social da propriedade sobre os interesses privados não é somente uma questão legislativa, mas de transformações nas práticas sociais e políticas.

\section{REFERÊNCIAS}

BRASIL. Estatuto da Cidade. Lei Federal no 10.257, de 10 de julho de 2001.

CORRÊA, R. L.. Região e Organização Espacial. $7^{\text {a }}$ Edição. São Paulo: Editora Ática, 2000.

IBGE. Regiões de influência das cidades 2007. Rio de Janeiro, 2008

LEME, M. C. da S. L.. (org.). (1999) Urbanismo no Brasil: 1895-1965. São Paulo: Studio Nobel; FAUUSP; FUPAM.

LEFEBVRE, Henri. O Direito à Cidade. $1^{\text {a }}$ ed. São Paulo: Moraes, 1991. 
LIMA, Fabio Jose Martins de. Urbanismo em Minas Gerais: Pelas Cidades. Juiz de Fora: Ed. UFJF, 2010. 210p. : II

MARICATO, E. Brasil. Cidades: Alternativas para a crise urbana. Cidade: Editora. Ano

NOVAIS, Pedro. Uma Estratégia chamada "Planejamento Estratégico": Deslocamentos espaciais e a atribuição de sentidos na teoria do planejamento urbano. Rio de Janeiro: 7Letras. 2010

ROLNIK, Raquel .Plano Diretor Participativo: Guia Para Elaboração Pelos Municípios e Cidadãos. Brasil. Ministério das Cidades. $2^{a}$ edição/ Coordenação Geral de ROLNIK, Raquel e PINHEIRO, Otilie Macedo. Brasília: Ministério das Cidades; Brasília: Confea, 2005.

SAULE JÚNIOR, Nelson \& UZZO, Karina. A trajetória da Reforma Urbana no Brasil. Banco de textos do Dialogues, Propositions, Histoires (DPH), 2009.

Endereços digitais do Plano Diretor Participativo de Lima Duarte:

Perfil - PDP Lima Duarte:

https://www.facebook.com/pdplimaduarte. planodiretor?ref=ts\&fref=ts

Grupo de debates - Plano Diretor Participativo de Lima Duarte - Debates:

https://www.facebook.com/groups/497156773678203/

Página - Plano Diretor Participativo de Lima Duarte/MG:

https://www.facebook.com/PDPLimaDuarteMG?ref=ts\&fref=ts 